\title{
Legal Reflection during the Crisis of the New European Worldview Paradigm: Problem Statement
}

\author{
Pavel S. Zhdanov
}

\author{
Vera B. Romanovskaya
}

Victor I. Tsyganov

\author{
N. I. Lobachevsky State University of Nizhny Novgorod, Russian Federation \\ Email: pavelzhdanov@bk.ru
}

\section{Doi:10.5901/mjss.2015.v6n3s5p79}

\section{Abstract}

This article touches upon the worldview basis of European identity in legal area. So it explores the issue of relationship between Western legal tradition and new European culture in the totality of it's multiform manifestations. Identification of this relationship gives us an opportunity to understand the character and reasons of the Western Legal Tradition crisis phenomena. It emphasizes the indissoluble connection between those phenomena and the global cultural processes, mainly the collapse of the former world view paradigm and formation of a new value system. The article also introduces a brief review of the development milestones of the 19th century philosophy, which were indicative of the start of revision of the major premises of the new European world view and the corresponding picture of the world. It is stated that there is an interconnection between those cultural processes and the crisis phenomena in legal consciousness, which started to take effect in the period of study and are thus seen as one of the manifestations of a deeper crisis in the new European world view fundamentals themselves. Besides, the article represents a review of a series of the legal concepts established by Russian authors in the first half of the 20th century, with common interest in the problem of legal consciousness during the crisis of European legal tradition.

Keywords: European identity, political and legal tradition, rationalism, crisis, ideology, historicism, humanism

\section{Introduction}

Today, the state that the modern theory of law is in, both in Russia and abroad, is often described using crisis categories. At the same time, any adequate understanding of the real scale of the problem is often impeded by the fact that the description of both the crisis phenomena themselves and their preconditions is limited by the bounds of juridical science. An example of such an approach is Harold J. Berman's description of the crisis in "the western legal tradition" (Berman 1998): confining himself to the description of the signs of decay of that tradition, the scientist passes over its general cultural preconditions, thus leaving the question regarding the reasons of the situation without any answer. A wider approach to describing the crisis phenomena characterizes the works of Leo Strauss, who makes the reasons of the crisis in the modern political (the same as legal) philosophy conditional on renunciation of the classical natural-legal doctrine and, as a result, dissemination of value relativism in the political legal reflection (Strauss, 2007).

However, we believe that the present-day crisis in legal awareness cannot be considered as only a revision of the established ideas or rejection of any systems of legal concepts, whether it is Marxist approach or pure normativism, or even the natural-legal doctrine. Today we should rather speak of a crisis in the worldview fundamentals of the legal reflection, i.e. the cultural system that gave rise to "the western legal tradition" which gained global importance by the middle of the $20^{\text {th }}$ century. The crisis mainly involved the system of thinking itself the bounds of which had been set by the ethical and cognitive values that had been the key features of the new European culture in its development period, during the transition from the Middle Ages to the modern era (first of all, we speak here of such major world view guidelines of the western civilization as humanism and rationalism). In particular, this kind of approach to describing the reasons of the decay of the ethics and law systems established in the conditions of the "sensate culture" can be found in P.A. Sorokin's The Crisis of Our Age (Sorokin, 2009).

The irony of the present-day situation is that with the basic set of the essential value notions preserved, the values themselves, which are meant by those notions, were subject to decay. Therefore the main feature characterizing the modern crisis in the legal reflection domain, as we have said, is not displacement of any points of view by any others but 
the disconnection between the language of the ethical-legal discourse and the actual content of the processes and relations that the discourse deals with.

This research has a double task. First, we have to describe, as concisely as possible, the genesis of the world view prerequisites of the modern crisis in legal reflection. Second, it appears reasonable to learn some examples of the last century legal concepts which, on the one hand, would be based on some clear understanding of the nature of the crisis phenomena and, on the other hand, would make a way to build a legal theory in the conditions of the new cultural reality.

\section{Methodology}

The character of the assigned tasks makes it impossible to perform just a chronological study of the content of the legal concepts as the internal cultural mechanisms which should determine the evolution of legal reflection would be left beyond the study then. The reasons of the crisis in the modernist paradigm of jurisprudence have to be detected through analyzing the process of the changes occurring to the thinking structures (the epistemes, according to M. Foucault) within which the legal notions are filled with certain meaning but beyond which they inevitably lose their viability. An important role in this study is also played by the methods developed by semiotics, in particular by considering a specific legal tradition as a historically established system of signs, which should be a "working" one, i.e. capable of expressing and communicating certain meanings, only as an organic part of the language of a particular culture.

\section{The New European Legal Tradition's Crisis}

\subsection{The preconditions}

It should be mentioned that certain decay of the fundamental categories of the new European culture has been observed for quite a long time already, and the major features of the upcoming crisis were clearly seen back in the late $19^{\text {th }}$ and early $20^{\text {th }}$ century (Weber, 1998; Jaspers, 1994; Manheim, 2010). So, with the beginning of the $19^{\text {th }}$ century marked with progressive disillusionment of the European society, first with the Enlightenment ideals and then with the rationalism principles in general (Berlin, 2002), at the end of the century we can see the collapse of the Renaissance image of man itself. In particular, extremely significant was the dissemination of the historical world view at the turn of the $19^{\text {th }}$ and $20^{\text {th }}$ centuries. This kind of world view relativized (which is particularly emphasized by Leo Strauss (Strauss, 2007)) the rationalist ideas of the unity and invariability of the laws of the universe and human society. The new sentiments found their external expression in the coming of romanticism, with its enhanced attention to the complicated and internally contradictory inner world of an individual. Hence, it came to replace the clear and rational forms of classicism which had been building the picture of the world where mind, relying on the objective laws of the universe, takes control of every irrational natural or social element. In philosophy of law, the new trends were represented, on the one hand, by the historical school of law which rejected rationalism in jurisprudence in favor of the organic view on the law as a part of the culture created by the public spirit and, on the other hand, by positivism which, instead of the ideas of the common and essential principles of the natural right, suggested the doctrine on the primary importance of the power that establishes the law.

But still, all those changes themselves could not lead to any total crisis in the fundamentals of the new European legal thinking or any crisis in the western legal tradition, for the former system of notions and values was still of considerable significance to subjects of legal reflection and legal relations. Or, in other words, as long as the minds of the Europeans preserved the system of the notions and signs, traditionally used to describe the legal reality, which was still filled with a living meaning and correlated with the system of their actual values of life.

The cardinal shift of the paradigm of the new European legal thinking occurred at the moment when the concept of the thinking subject was itself subjected to revision and when the ideas of the subject that is capable of perceiving the truth about the reality were replaced by the ideas of the subject whose thinking is totally determined by the social environment. That did not only mean doubts about the possibility of understanding the social and legal phenomena but also, to a large extent, rejection of a whole series of the key philosophical thinking principles which were established in the post-Renaissance period and determined the character of political-legal reflection.

It was exactly the meaning that was acquired by the "ideology" concept that appeared in the first half of the $19^{\text {th }}$ century. Reconsidered by Marx and Engels, it was demolishing the idea of the subject's cognitive activity being direct and controlled by the subjects. As they said, "even hazy structures appearing in the minds of people represent essential products, a kind of evaporations of their material life process, which can be determined empirically and is connected with material prerequisites" (Marx \& Engels 1970, p. 14). Morals, religion and metaphysics, which are enunciated as sorts of 
ideology, lose their independent character in the eyes of the founders of dialectical materialism and are thought to be reflexes of material production. "It is not the consciousness of men that determines their being, but, on the contrary, their social being that determines their consciousness" - that is the major thesis of Marx's theory of knowledge. Although ideology passes itself off as the aggregate of knowledge about the real world, it however performs another function that is far from the cognitive process: it serves for uniting people into social structures of various types (Mamardashvili, 2010, $\mathrm{p}$. 63). Moreover, ideology puts every possible obstacle in the way of understanding the grounds of those social relations and raising the question on the appropriateness of the established order. This meant that not only any theory but also any system of values were class-dependent, so it was unnecessary to even raise the question on their verity or falsity. Ideological consciousness is not aware of the truth about itself as, when speaking of the objective reality, it only expresses the opinion caused by the class interests. Consciousness, which was seen clear and transparent by classical philosophy, providing it is free from the influence of any affects, now appears penetrated by relations that it cannot control (Mamardashvili, 2010, p. 72). Looking at the law through the prism of the conception of ideology does not only mean relativization of its value-related fundamentals but also denying the possibility to speak of the law from the position of any objective values in principle. According to Marxism, it is not the mind that we see as the basis of the law, and it is not even the will in its pure form, but it is the material relations, which find their ideological reflection in every product of the spiritual activities of men.

Friedrich Nietzsche subjected the prerequisites of the new European world view to no less radical revision. His statement "God is dead" meant radical rejection of the references to the ideal reality and some sort of a supersensory world as the substantiation of the values, which he thought had been an unwavering metaphysical premise since Plato's times. Hence, "God is dead" was expected to serve for the start of revaluation of the former supreme values. Nietzsche defines the value itself as "a viewpoint" that "is always defined by viewing and for viewing" and does not exist beyond recognition (Heidegger, 2008, p. 322). The new definition of 'value' should be based on the "will to power" which means, above all, responsibility and will to self-determination.

The new European man is also criticized. According to Nietzsche, "Man is something that shall be overcome" (Nietzsche, 1990, p. 8). In other words, he believes that the image of man in itself, which has been the main guideline of the European thought since the Renaissance, cannot be the objective. "Man is rope stretched between the animal and the Overman". "What is lovable in man is that he is an over-going and a down-going" (Nietzsche, 1990, p. 9). Thus, Nietzsche declares the death of both the former system of values, which, in actual fact, turned to be idols hiding their inner emptiness behind the references to the absolute viewpoint of the ideal reality, and the subject himself who had been asserting those values. Nietzsche denies the idea of the progressive development of mankind and interprets history by using the categories of the "eternal comeback", thus stating the fact of the decline of the European culture.

The revaluation of the Renaissance image of man by F.M. Dostoyevsky was no less radical either. He was one of the first who could feel how deep was the spiritual crisis that the European culture had sunk into (Rozanov, 2013; Shestov, 1993). The sinister figure of the "underground man" depicted by the Russian writer leaves no room for the former optimistic anthropocentrism and brings to naught all the basic prerequisites of the rationalist ethics, such as the conception of the interconnection between a clear judgment and a lawful deed. Hence, the determining power of the moral law appears ineffective in the face of the irrational freedom of man. S. Freud's discoveries were also of comparable importance to the transformation of the image of man in the modern culture (Mamardashvili 2010, p. 306): they revealed the significance of the extramental processes taking place in the human mind and the effect they have on man's behavior, as well as the acuteness of the conflict between man's nature and civilization, which makes every individual's life in the society a permanent source of traumatic situations (Brinton, 2003, p. 368).

Thus, we can observe the unfolding picture of the decay of the very fundamentals of the new European world view. The ideal image of man, who learns the truth and builds his life based on the fundamentals of mind, is subject to revision (Mamardashvili et al., 2010, p. 129). The essential postulates of the theory of knowledge, which were established in the Rationalism and Renaissance eras, are being demolished (Nisbet, 2007, p. 520), and the system of values is losing its integrity and absoluteness. So, speaking of the crisis of the law or legal consciousness at the turn of the $19^{\text {th }}$ and $20^{\text {th }}$ centuries, one should keep in mind that the heart of the crisis did not consist in disappointment at any specific institutions or ideas, or not even in devaluation of the key legal values, but in demolition of the world view frames within which the legal tradition had been reproduced at the subjective and collective levels as the unity of the normative, theoretical, psychological and axiological aspects during the past centuries.

\subsection{The legal reflection}

Understanding the reasons and the character of the crisis phenomena (both in legal reflection and in other domains of 
social and liberal knowledge) was only possible as the researcher could deliberately go beyond the limits of the classical new European cognitive paradigm, without being restrained by the traditional system of ideas and notions that did not provide any possibility to describe the essence of the actual events in any adequate way anymore, to say nothing of defining any ways out of the crisis situation. The latter was even more difficult as it required reconstruction of the experience of substantiating the law during the formation of the new world view structures. As a matter of fact, the task of the non-classical science of law was to re-discover the law in a brand new way.

In the light of the above, the theories of law which were created in the early $20^{\text {th }}$ century and represent attempts to consider the law from the viewpoints of the new cultural reality are of special interest. The common feature of those theories was, first, a wide use of the theoretical arsenal of the new philosophic trends (phenomenology, psychoanalysis, existentialism, and others) and, second, trying to understand, above all, the subjective experience itself from which individuals learn and accept the key legal values. A series of striking examples of establishing a system of legal views during the total world view crisis can be found in the Russian philosophy of the first half of the $20^{\text {th }}$ century.

First of all, we should mention Nikolay Alexeyev's (1879-1964) concept based on applying the phenomenological approach to the study of legal phenomena. Following the phenomenological guideline, Alexeyev rejected the right to define the law from the purely logical positions, which had been typical of rationalist philosophy. It corresponded to his view of the nature of philosophy, which is a world outlook, i.e. "not only the aggregate of the theoretical verities but also an act, historical or personal" (Alexeyev, 1998, p. 40). Instead of a chain of rational definitions leading to infinity, the theory of law should be based on the indefinable "initial realities" of the law, which can only be watched and described. Only if we watch them directly, we get values which represent qualitative realities that are not determined logically but are obvious with their objective character at the same time (Alexeyev, 1998, p. 54). The experience that represents the primary content of the law consists in subject's recognizing the values and in "concerned attitude" towards them. And the definitions of such attitude are legal authorities and legal obligations as the required initial indefinable realities. As for the values, according to Alexeyev, their nature consists in the embodiment of the otherworldly being in the real world and experience (Alexeyev, 1998, p. 107). Alexeyev insists that perceiving the values should result exactly from their objective experience: the subject should find them, not invent them. The form in which the legal meaning finds its expression is the numerous normative facts that are capable of obliging people to perform specific actions.

So, Nikolay Alexeyev emphasizes the objective character of the values building the foundation of the law and pays great attention to the subjective aspects of perceiving their reality. It is obvious that the act of recognizing the values and experiencing them intuitively requires that the subject should have certain qualities and develop some sort of sensitiveness to those values. In this context, spiritual life and "sound legal consciousness" are indivisible. Therefore, overcoming the legal consciousness crisis mainly presupposes a subject that would be able to accept the values independently and responsibly. Alexeyev declares that "if a legal subject is perfect and if he goes through and realizes his legal experience in the right way and implements its results, the positive system of the law cannot but be perfect in its content" (Alexeyev, 1998, p. 206). He cites, with sympathy, Ivan llyin's opinion that "as a matter of fact, the law and the state live inside the subject of the law; they only live together with him, with the subject, with his soul and with his spirit" (Alexeyev, 1998, p. 204).

The issue of the personal attitude towards the law was developed in detail in the works of Ivan llyin (1883 - 1954) (Zhdanov \& Romanovskaya, 2012, pp. 128-133). Accepting the phenomenological methodology in many respects, he also pays great attention to describing the experience in which individuals understand the law as a spiritual value. The philosopher points at the fact that the basis of the "sound legal consciousness" should consist in the individual's experiencing the legal values directly and accepting them freely. To define the ability to understand the basic principles of the law, he uses the term "natural legal consciousness" which, being an "instinctive sense of law" (llyin, 2006, p. 281), belongs to every man providing he has developed that skill spiritually inside himself. This level of legal consciousness has to be cultivated in the individual; this is exactly what shows his spiritual maturity and independence. It is based on the sense of your own spiritual dignity and your ability to be autonomously self-obliged, and on your recognizing the dignities and values of other individuals (llyin, 2006, p. 281). Legal consciousness, when it reaches the proper level, becomes a guarantee of not just the right understanding and independent recognition of the law but also its creative use: when the subject follows the spirit of the law, not its letter. At the same time, llyin considers the respect for the law as the respect for its essence, which applies to its transient forms as well.

It is obvious that a high level of legal consciousness means a high level of the general spiritual development of the person. According to llyin, the will to the law is only a particular manifestation of the will to the spirit (llyin, 2007, p. 315). In this context, creative legal consciousness is a phenomenon of the same structure, a true philosophical experience, and moral sensitiveness. The pivot that connects all those spiritual aspects of man's life is the religious faith. Only a true spiritual experience creates preconditions for the discovery of objective values. Therefore, the semantic core of llyin's 
theory of legal consciousness is the issue related to education of a subject that would be able to recover his legal experience in its ingenuousness and integrity. In the conditions of spiritual disorganization of the European man, this kind of way was seen as the only promising one: it is impossible to establish any new grounds of the law without developing an integral world view, a system of values where the law should find its place and meaning.

The same idea can be clearly traced in the ethical and legal concepts developed by other religious thought representatives. So, in the context of the Russian religious philosophy, special attention is paid to the attitude of a person towards the external heteronomous norms. Based Z. Freud's studies, Boris Vysheslavtsev (1877-1954) discovers a new meaning of the old Christian teachings of the law and God's grace. He says that law, in the broad sense, is always percieved as something which is forced from the outside and, with its demands to the consciousness, meets with resistance at the subconscious level (Vysheslavtsev, 2006, p. 66). So, the law can only be effective if it is ensured by the forced power of the public authority but can never eradicate the original cause of a crime from the man's mentality. Unlike the heteronomous law, the grace, considered as the power of love to God and man, is able to make effect on the subconsciousness and redirect its destructive energy to a creative course by turning the irrational freedom of denying into creative freedom. Thus, Vysheslavtsev comes to the conclusion that the normative prescriptions of the law will inevitably meet with rejection in the man's soul unless they are brought into correlation with a system of values which should be freely adopted by the man.

The problem of social communication is related to the personal attitude towards the social norms. According to Semyon Frank (1877 - 1950), a person, as "I", finds him- or herself in communication only, when meeting "you"; "it is determined by the act of differentiation" (Frank, 1992, p. 50). And the possibility of this kind of meeting lies in the primary unity of the common "we" which is "unity of the categorically heterogeneous personal being, of 'I' and 'you"' (Frank, 1992, p. 51). We are given human life as public life only, which is the essential expression of "the deepest common unity that man's being is based on" (Frank, 1992, p. 53). The spiritual nature of a society, or the fact that a society is based on the general internal unity of men, makes for an ambiguous expression of the integral fundamentals of the due. On the one hand, it is given directly to the man's spirit and, on the other hand, it applies to it in the form of social norms of transcendent and objective character (Frank, 1992, p. 83). This ambiguous character is a guarantee of the possibility for an individual to freely accept the heteronomous requirements, with the individual finding the meaning of those requirements in a system of values which is immanent in his consciousness.

That has a lot in common with Nikolay Alexeyev's views on the nature of the social character. He emphasized the fact that the precondition for the social unity is the presence of values which are shared by every member of the society and of "a shared historical ethos" as this is exactly the value domain where the individual meets with the social. On the other hand, the obliging power of the ethos phenomena originates exactly from the inner unity of men. According to Alexeyev, "only the idea of the integral and the necessity which comes from it can explain that mysterious and amazing phenomenon of the absolute ethical and legal connection" (Alexeyev, 1998, p. 150).

\section{Concluding Remarks}

Summing up the above review of the legal concepts of the period when crisis phenomena in the European culture first became a recognized reality, we can mention a series of their common features. In the conditions when the legal consciousness tradition based on the modern era world view appeared interrupted, philosophy of law found itself in the face of the necessity to rebuild the entire system of the experience in the context of which the grounds of the law were introduced. This was related not only to the system of the values that determined the meaning of the law but also to the subject who had lost the value self-orientation and self-determination skills during the period of a total collapse of the established world view structures. Establishing a new, non-classical rationality type for the consideration of subjective factors in the cognitive process pushed the issue of the personal attitude towards the law to the foreground. So, considering the fact in which the subject perceives the reality of the legal values and forms his attitude towards them is becoming the meaningful center of the studies. According to the opinions of the authors reviewed in this article, the lost faith in the objectivity of the fundamentals of the law can only be restored in the context of personal spiritual renaissance in the new cultural conditions. And of course, the spiritual self-determination act for which the modern man was appealed to could not be absolutely unfounded: it rather dealt with reconsideration and reanimation of the traditions that had been feeding the European culture since the earliest times. The Christian motives characterizing the philosophical views of I.A. llyin, B.P. Vysheslavtsev and S.L. Frank become intertwined in their world outlooks with the new European humanism. But what is of fundamental importance to them is the belief that during a crisis traditions cannot be preserved "automatically" as they require personal sympathy of interested individuals and have to become firmly established by their personal, if you please, "existential" choice. Only by means of individual acceptance man can restore the meaning of the 
values, institutions and norms of social life: the meaning that was being watered down during the decay of the world view that had brought them to life.

No matter what is our own attitude towards particular conceptions on which the abovementioned authors built their legal views, we have to remember the main thing: they clearly understood that the crisis of legal science and the crisis of legal consciousness were not particularly legal issues. Caused by the general decay of the new European world view paradigm, the above phenomena could not be overcome within the former system of values or without a deep revision of the essential categories that legal reflection had been based on and that had lost their vitality and meaning in the eyes of the present day individual. Hence, the modern legal theory, which is deprived of the ability to appeal to the value categories of the modern era, is forced to put the question on the place of law in the man's life and in the system of culture all over again.

\section{References}

Alexeyev, N.N. (1998). The Fundamentals of the Philosophy of Law. Saint Petersburg.

Berlin, I. (2002). Counterenlightement. In: I. Berlin (eds.) The True Purpose of Cognition. Selected Essays (pp. 261 - 295). Moscow.

Berman, H. J. (1998). The Western Legal Tradition: the Formation Stage. Moscow: Moscow University Publishing House.

Brinton, C. (2003). The Origins of the Western Way of Thinking. Moscow.

Frank, S.L. (1992). The Spiritual Fundamentals of a Society. Moscow.

Heidegger, M. (2008). Nietzsche's Word "God Is Dead". In: M. Heidegger (eds.) The Origin of the Work of Art (pp. 302-368). Moscow. Ilyin, I.A. (2006). On the Essence of Legal Consciousness. In: I.A. llyin (eds.) General Teaching of Law and State (pp. 180-508). Moscow Ilyin, I.A. (2007). The Way to Spiritual Renovation. In: I.A. Ilyin (eds.) Why We Believe in Russia: Works (pp. 123-375). Moscow.

Jaspers, K. (1994).The Spiritual Situation of the Time. In: K. Jaspers (eds.) The Meaning and Purpose of History (pp. 288 - 420). Moscow.

Mamardashvili, M.K. (2010). Essay on the Modern European Philosophy. Moscow.

Mamardashvili, M.K., Soloviev, E.Yu., \& Shvyrev, V.S. (2010). Classical and Modern Bourgeois Philosophy (Experiment in Epistemological Comparison). In: M.K. Mamardashvili (eds.) Classical and Non-Classical Ideals of Rationality (pp. 125-183). Saint Petersburg.

Manheim, K. (2010). Diagnosis of Our Time. In: K. Manheim (eds.) Selected Works: Diagnosis of Our Time (pp. 538 - 707). Moscow.

Marx, K., \& Engels, F. (1970). Selected Works in 3 Volumes. Vol. 1. Moscow.

Nietzsche, F. (1990). Thus Spoke Zarathustra. In: F. Nietzsche (eds.) Works in 2 Volumes. Vol. 2 (pp. 5-238). Moscow.

Nisbet, R. (2007). Progress: the History of the Idea. Moscow.

Rozanov, V.V. (2013). F.M. Dostoyevsky's The Legend of the Grand Inquisitor. In: V.V. Rozanov (eds.) Works: [Vol. 3] F.M. Dostoyevsky's The Legend of the Grand Inquisitor and Other Articles: 1891 - 1892 (pp. 30 - 230). Moscow.

Shestov, L. (1993). Dostoyevsky and Nietzsche. In: L. Shestov (eds.) Selected Works (pp. 159 - 327). Moscow.

Sorokin, P.A. (2009). The Crisis of Our Age. The Social and Cultural Outlook. Moscow.

Strauss, L. (2007). Natural Right and History. Moscow: Vodoley Publishers.

Vysheslavtsev, B.P. (2006). The Ethics of the Transfigured Eros. In: B.P. Vysheslavtsev (eds.) The Crisis of the Industrial Culture: Selected Works (pp. 21-195). Moscow: Astrel.

Weber, A. (1998). Germany and the Crisis of the European Culture. In: A. Weber (eds.) Selected Works: the Crisis of the European Culture (pp. 169 - 199). Saint Petersburg.

Zhdanov, P.S., \& Romanovskaya, V.B. (2012). The Ethical and Legal Concepts in the Russian Religious Philosophy of the Late $19^{\text {th }}$ and the First Half of the $20^{\text {th }}$ Century. Nizhny Novgorod: N. I. Lobachevsky State University of Nizhny Novgorod. 